\title{
Promoting Communicative Skills and Cultural Understanding among Saudi EFL Students Joining Summer English Programs at US Universities: A Web-Based Project
}

\author{
Sami Ali Nasr Al-wossabi \\ English Department, Faculty of Arts and Humanities, Jazan University, Jazan, Saudi Arabia \\ E-mail: sami_ed@hotmail.com
}

Doi:10.7575/aiac.alls.v.7n.6p.36

URL: http://dx.doi.org/10.7575/aiac.alls.v.7n.6p.36
Received: 22/08/2016

Accepted: 28/09/2016

\begin{abstract}
As English is one of the most spoken languages in the globally interconnected world of today, many Saudi universities are enrolling their EFL students in summer intensive English programs at US universities. The main purpose is to enhance their EFL students' oral competencies. This new policy is, in fact, the result of the failure of CLT practices in local universities (Liao, 2004; Nunan, 2003), large EFL classes and students' low proficiency (Yu, 2001; Li, 1998) and EFL teachers' preference for using traditional methods rather than communicative ones (Chowdhry, 2010; Littlewood, 2007). However, Saudi students, upon arrival to the US, encounter challenging communicative situations. The present study, therefore, advocates the implementation of four-week language software program in Jazan university prior to the later four-week language program in US universities. The aim is to prepare EFL Saudi students for the communicative and academic situations and cultural norm they would be encountering and experiencing in the USA. The project includes two modalities; online learning and in class learning. The online learning entails a language software contentbased program with emphasis on listening, vocabulary, writing, grammar and reading skills. The in-class learning includes only speaking activities that are paralleled and compatible to the online thematic content. Thus, the main focus of the present paper will primarily be directed to providing a detailed description of the online language software and the different elements involved in constituting it.
\end{abstract}

Keywords: language software components, integrated skills, communicative competencies, intensive language programs, cultural and sociolinguistic norms

\section{Introduction}

Due to the significance and importance of English as the most widely spoken language in the world, Saudi universities are noticeably coordinating with American universities to register their students in summer intensive English programs held at these universities. Being selected for such language programs is highly competitive and nominees are expected to have a good command of English. However, most of the nominees lack the ability to communicate purposefully and meaningfully in the target language. This insufficiency in producing oral output is, in fact, one of the main reason that lies behind sending Saudi EFL students to intensive English programs at American universities.

However, most students when returning back revealed that they have encountered many challenging communicative and academic situations and speech behaviors where they lacked proper linguistic devices and sociolinguistic rules necessary to sustain conversations and avoid communication breakdowns.

Hence, the present project proposal suggests that students need to be prepared linguistically and culturally prior to travelling to the US. The project involves two modalities. One mode is the online language software which is meant to integratively enhance students' language skills (listening, reading, writing, grammar and vocabulary) and promote cultural understanding of American culture and customs via the use of authentic language materials. The second is in class speaking activities which will take place mostly in regular classes. Speaking activities will foster oral practice of topics that students have already taken in the online language software. Web site activities and in class activities are aligned with the four-week curriculum at the US University and will provide students with opportunities for interactive practice of language in use. The two modalities of the project also entails the use of American speech conventions and behaviors, communication strategies and speaking rules to avoid any misunderstanding or miscommunication on the part of students.

The focus of this project proposal is on the web-based language software and the different elements necessary for structuring it since the in class activities are only used to practice and perform the web-based activities. What follows is then a detailed account of the different components of the four week language software program proposed as a complement for the curriculum that Saudi EFL students are going to undertake at an American university. 


\section{Teaching Scenario}

This project proposal is based on the learning scenario which takes place in an EFL Saudi setting at Jazan University. This four-week web-based learning project is designed to complement the curriculum for an established intensive English four-week summer program held at US universities. Thus, the selected students for this program spend the first four weeks studying English on campus for 20 hours a week. For the final four weeks of the program, the students travel to a university campus located in an American university. During this immersion period, students live with American families and take classes at the university's English language institute.

The students' proficiency levels range from high intermediate to low advanced. Their ages range from 20 to 22 years of age and have all completed at least three years of university coursework. There are 30 male students in the program. Students will be divided into groups of 15 so that the learning process will be more productive and effective. All of the students have strong grasp of English as they are to be selected based on interviews conducted at the English department at Jazan University.

The students have a good background in reading, writing, and grammar; however, they are in great need to develop their listening and speaking skills in order to communicate effectively. There are five teachers in the summer program. Two of the teachers are native speakers of English and the other three are from different backgrounds. All of the teachers have advanced degrees in Teaching English as a Second Language. Some of the teachers will travel with the students from Saudi Arabia to the United States and work cooperatively with ESL instructors at an American university.

\section{Components of the proposed language software}

\subsection{Goals and Objectives}

First and foremost, the web site will parallel the program's curriculum goals and objectives, which incorporates a content-based approach to communicative language learning. The curriculum is based on American culture and customs. Web site activities are aligned with the curriculum and will provide students with opportunities for integrated skills practice which will emphasize listening, reading, writing, grammar and vocabulary and will use authentic language materials. In class exercises will reinforce speaking and pronunciation practice. Exercises will include writing practice with pen-pals, in chat rooms, and pronunciation practice, grammar drills, and listening practice. Exercises will provide multiple choice, short quizzes, and fill-in-the blanks questions and will give feedback.

\subsection{Amount of Instructional Time}

Students are required to complete five hours of computer work each week, during the four weeks period of instruction, which begins on campus in Jazan University. Then, the final four weeks of the program are completed at an American university. The web site activities are designed to be used to serve two different modalities. First, they can serve as supplementary materials to reinforce classroom instruction as homework or in class assignments. Second, the purpose of asking students to work on the tasks on their own pace is to encourage them to become autonomous learners.

\subsection{Learning Potential}

The web site lesson plans will take a learner-centered approach and will provide students with opportunities for learning with focus on form and meaning, developing learning strategies and producing output (Chapelle, 2001). The different exercises and activities offered in each lesson will promote not only cultural information, but also the use of the target language that will be applied and used in real life situations while studying in the US. One of the goals for presenting different tasks is to expose learners to authentic language models in order to promote acquisition and increase their motivation and self-confidence (Chapelle, 2001). In addition, the study is providing authentic L2 learning tasks which will be very similar to the tasks learners will encounter in their USA experiences (Alessi \& Trollip, 2001). The activities will not only provide learners with opportunities for reading and writing practice, but also will develop effective communicative skills and metacognitive strategies to enhance learners' accountability while promoting active and discovery learning (Alessi and Trollip (2001). None of the exercises will be timed. Therefore, students will be able to repeat taking the exercises and practice the language skills, as many times as necessary, depending on their individual differences, their level of comfort using computers and their level of proficiency. The feedback is designed to be constructive and will include different types of reinforcements such as Correct! or Sorry, try again! to encourage students to keep working with the exercises and to keep the affective filter low. The feedback is meant to motivate students to continue with the activities and that each student will experience their own language learning success.

\subsection{Meaning Focus}

As Chapelle (2001) claims, the meaning focus of the web program requires learners to use the target language to carry out the different learning tasks. The objective for learners is to "construct and interpret meaning" using the target language in order to develop language skills" (p. 56).

\subsection{Types of Learning}

As Alessi and Trollip (2001) suggested, the activities should reflect everyday language in use and that they should provide students with communication strategies that students will need to use during and after the completion of the program. In order to help prepare EFL Saudi students for the academic community and address different learner types, the web project will provide clear instructions, grammatical and vocabulary exercises, the practice of all four language skills, and activities such as problem-solving, fill in the gaps, and taking notes to help students develop cognitive strategies (Richards, 1996). 


\subsection{Teaching Methodologies}

The methodologies identified for this web site will combine tutorials, drills, and writing practice which will take place in both chat rooms and through email to instructors, and with pen pals. All activities and exercises are chosen based on the functional capabilities of the web site. Since the program is separated into a four- week course of study, each week has a different instructional theme. The first week will focus on issues concerning living in the United States. The theme for the second week will concentrate on the American family, while the third week will be dedicated to American communicative styles. The fourth week will highlight the American educational system. The weekly web site lessons will emphasize listening, reading, grammar, vocabulary and writing practice while the in-class language instruction will provide speaking and pronunciation practice.

Factor decisions are based on suggestions from Alessi and Trollip (2001) and will include the following categories: introduction, learner control, presentation of information, and ending a program (p. 48). The goal is to incorporate language use throughout the web site and in the exercises, which is authentic, at or close to the students' proficiency level. Moreover, the program will foster learners to have the power to continue or end an exercise; move easily from one activity to another, or to be able to exit the program at any time. In order to help teachers track students' progress, students will be asked to print the assignments and bring them to class next day or email them to their instructors.

The web site's introduction will provide information about the program's instructional goals and will be used to advertise the program to parents and potential students. It will also contain links for program contact information. The general information will be available both in English and Arabic so parents of students will be informed of the program's goals and objectives, courses, tuition and fees (see Appendix C).

The navigation process will be consistent and the students will have control at all times. Learners will use a mouse to navigate to other pages and to access the program's menu which can be found on the left hand side of each page. Forward and Back buttons will be placed conveniently on the bottom of each page and will be available to students throughout the program.

\subsection{Evaluation Form}

For this web-based project, the evaluation form will be updated periodically to assess the project's quality, its practicality, its adaptability and its appropriateness to the above mentioned scenario (see Appendix A). The content of the evaluation form incorporates some sections adapted from Alessi and Trollip (2001) such as subject matter (e.g., clearly stated goals, content accuracy), interface (e.g., displays, presentation modes). However, some of the features adapted from Alesi and Trollip (2001) are expanded by adding other features. For example, the methodologies item in the pedagogy section now asks if opportunities for listening, speaking, reading, and writing practice are present. Such features are indeed important to be included in the project's evaluation form as they reflect the project's emphasis on incorporating the four target skills in this educational scenario.

With regard to the format, the evaluation form includes two sections. The aim of the first section is to gather basic information such as the name of the program, reviewer's name, and the date. The aim of the second section is to have a constant evaluation of the project and to get an in depth view of its design, quality, practicality and appropriateness to the target students. This section includes several categories mentioned above and it is presented in the form of a table. All categories in the second section include space for the reviewers to add their comments which would help determine if particular sections or features need further revision.

\subsection{Style Conventions}

Since the prospective users of this web site are second language learners who plan to enter American universities in the future, specific consideration are given to their technical knowledge of computers, second language background and particular style conventions for grammar, punctuation, spelling, language, cultural, and graphics. For grammar, the program is using active voice, present tense, and the imperative. APA style is used for punctuation and spelling. The language used is not gender specific. The program also strives to promote cultural understanding and respect as the web site's language considers the native culture and norms of the students. Because of the age range of the students, graphics are also used to motivate, challenge, and keep students' interests.

\subsection{Functionality}

To increase the practicality of the software, the tendency is to limit the amount of information to 40 kilobytes per screen. If a screen includes a large amount of data, it will be a slow and tedious process for learners to access the software. Furthermore, the program keeps certain keyboard conventions such as F1 for Help so students have locus of control at all times. The program also ensures that students can use both the keyboard and mouse to navigate the program.

\subsection{Look and Feel}

On each screen of the proposed language software, the school's logo will appear with Arial font style and in 36 point font. The school's logo contains multiple colors, with a light gray shadow. The theme page of the software will display pictures of the university campus life and activities where students are going to study in the USA. Next, the font style, color, and size of texts of each page are arranged left, using 12 point, Times New Roman font. Different five levels of headings are used and are as follows: level 1 heading is 24 point, level 2 is 18 point, level 3 is 14 point, level 4 is 12 point, and level 5 is 10 point. The color of the headings is black and the font is Times New Roman. Also, each page will utilize the theme Cascade because of its strong appeal to young generation. Moreover, the layout of each page is 
determined to have the button "Menu" at the left side of the page. From "Menu", users can browse or use the software. Also, each page will have the button "Back", "Forward", and "Exit" at the bottom of the page. Using these buttons, users can navigate easily throughout the web site (see Appendices B \& C).

Under the Lessons heading, users can find four weeks of instruction that are described as follows: Week \#1 (Life in the US), Week \#2 (American family life), Week \#3 (American communicative styles), and Week \#4 (American educational system). Each week contains five lesson plans which focus on different combination of skills and activities, including listening, reading, writing, grammar and vocabulary (see Appendix B). The Glossary button contains the vocabulary included in the readings.

\subsection{Primary/secondary texts}

For this project, primary text displays will represent the actual instructional content of the software. Texts such as passages, definitions, and exercises that involve new information and concepts about American cultural aspects are included. These texts are adapted from Datesman et al. (1984), Althen et al. (1998), and Abraham and Mackey (1982), in addition to other texts taken from accredited web sites and various ESL textbooks. In selecting and adapting these texts, the software program is considering that they should be briefly written and must address particular cultural aspects that students need to know for their prospective learning settings. The aim is to keep the student motivated while dealing with these texts (see Appendix D) in the form of drills, true/false and multiple-choice are other types of primary display texts that are used to elicit responses from students about the content of their texts. They are also designed to enhance their language skills, enrich their content knowledge, and reinforce their learning experiences. The type of questions contained in these texts is meant to be appropriate to students' level, clear, concise and interesting. Moreover, texts that display feedback are also designed to be positive, and to the point.

Secondary texts messages such as directions, menus and prompts are included as to help learners understand their texts and monitor their progress. These texts usually accompany the primary texts as to direct students in how to go about their texts. These additional types of secondary texts are placed at each unit and serve as a directory section for students. The aim is to provide learners with some general tips that guide them in their learning processes of the software content (see Appendix D).

\subsection{Support Material: Instructor Manual}

The main aim of this software is to support the program's curriculum goals and objectives, which incorporates a content-based approach to communicative language learning. Another purpose of this software is to raise students' awareness of American culture and customs in order to facilitate their forthcoming real life experiences in the US. The topics for this software have been selected to meet students' needs and interests in this particular ESL setting. The content materials are divided into four main themes: Life in the US, American family life, American communicative styles, and American educational system. Each theme will be completed in one week. Five (60minutes lessons) are designed for each theme. Activities included in each theme will provide students with opportunities for integrated skills practice. Exercises will include listening, reading, grammar, vocabulary, and writing and practice by using authentic materials associated with these topics. Speaking and pronunciation exercises are practiced in class. Teachers are encouraged to use the activities as supplementary materials to reinforce classroom instruction as homework or in class assignments. Students must complete five mandatory hours of computer work each week.

\subsection{Equipment needed}

The program can be used with PC computers that are connected to the Internet. Its applications are downloaded at the PCs of the university language labs. Students will be able to record their progress by printing the assignments or by sending them to their instructors via email.

\subsection{Normal running of the program}

To see the program's content, themes, lesson plans, activities and transitions, teachers can consult the flowchart that describes the program's design (see Appendix C).

\section{Conclusion}

Generally speaking, this web-based project along with the in class speaking activities is designed to benefit Saudi EFL students in continuing professional enhancement of their academic, communicative and sociolinguistic competencies whether they are already members in a target language group or still in their interlanguage groups at their local communities. Further, it is an attempt to draw the attention of officials and administrators to the potentials of such language programs in easing the students' developmental processes in learning and using the target language purposefully and meaningfully.

Indeed, equipping our students with the necessary communicative and academic skills and interactional practices would ensure the best academic performance on their part during and after the completion of such overseas language and cultural immersion programs.

\section{References}

Abraham, P. \& Mackey, D. (1989). Contact USA. Reading and vocabulary textbook (2 ${ }^{\text {nd }}$ ed.). Englewood Cliffs, NJ: Prentice Hall Regents

Alessi, S., \& Trollip, S. (2001). Multimedia for learning. Boston: Allyn and Bacon. 
Althen, G. (2003). American ways: a guide for foreigners in the United States. Maine: Intercultural Press.

Chapelle, C. (2001). Computer applications in second language acquisition. NY: Cambridge University Press.

Chowdhury, R. (2010). International TESOL training and EFL contexts: the cultural disillusionment factor. Retrieved September 25, 2015, from http://www.eltworld.net/times/2010/09/international-tesoltraining-and-efl-contexts-the-cultural-disillusionment-factor

Datesman, M. K., Crandall, J., \& Kearny, D. N. (1984). The American ways: An introduction to American culture. NJ: Prentice Hall.

Li, D. (1998). It's always more difficult than you plan and imagine: Teachers' perceived difficulties in introducing the communicative approach in South Korea. TESOL Quarterly, 32(4), 677-703. http://dx.doi.org/10.2307/3588000

Liao, X. (2004). The need for communicative language teaching in China. ELT journal, 58(3), $270-273$. http://dx.doi.org/10.1093/elt/58.3.270

Littlewood, W. (2007). Communicative and task-based language teaching in East Asian classrooms. Language Teaching, 40, 243-249. http://dx.doi.org/10.1017/S0261444807004363

Nunan, D. (2003). The impact of English as a global language on educational policies and practices in the Asian-Pacific region. TESOL Quarterly, 37(4), 589-613. http://dx.doi.org/10.2307/3588214

McCarthy, M., O’Dell, F., \& Shaw, E. (2000). Vocabulary in use: Upper intermediate. NY: Cambridge University Press.

Richards, J. (1996). Reflective teaching in second language classrooms. NY: Cambridge

Yu, L. (2001). Communicative language teaching in China: Progress and resistance. TESOL Quarterly, 35(1), $194-198$.

\section{Appendix A \\ Evaluation Form}

\section{EVALUATION FORM}

Program:

Reviewer:

Date:

\begin{tabular}{|l|l|l|l|}
\hline \multicolumn{1}{|c|}{ ITEM } & Acceptable & $\begin{array}{c}\text { Needs } \\
\text { work }\end{array}$ & \\
\hline Subject Matter & & & \\
\hline Matches goals & & & \\
\hline Content structure & & & \\
\hline Content accuracy & & & \\
\hline Content sequencing & & & \\
\hline Content transitions & & & \\
\hline Style conventions & & & \\
\hline Grammar & & & \\
\hline Punctuation & & & \\
\hline Spelling & & & \\
\hline Reading level & & & \\
\hline Cultural bias & & & \\
\hline Technical terms & & & \\
\hline and jargons & & & \\
\hline Glossary & & & \\
\hline Adaptability to curriculum & & & \\
\hline
\end{tabular}

\begin{tabular}{|c|c|c|c|}
\hline \multicolumn{1}{|c|}{ ITEM } & Acceptable & $\begin{array}{c}\text { Needs } \\
\text { work }\end{array}$ & Comment \\
\hline Auxiliary Information & & & \\
\hline Introduction & & & \\
\hline
\end{tabular}




\begin{tabular}{|c|l|l|l|}
\hline Instructional objectives & & & \\
\hline User directions & & & \\
\hline Examples and & & & \\
Demonstration & & & \\
\hline Conclusion & & & \\
\hline
\end{tabular}

\begin{tabular}{|l|l|l|l|}
\hline \multicolumn{1}{|c|}{ ITEM } & Acceptable & $\begin{array}{c}\text { Needs } \\
\text { work }\end{array}$ & Comment \\
\hline \multicolumn{1}{|c|}{ Affective considerations } & & & \\
\hline Motivation & & & \\
\hline Authenticity & & & \\
\hline Learner accountability & & & \\
\hline Level of engagement & & & \\
\hline
\end{tabular}

\begin{tabular}{|c|l|l|l|}
\hline \multicolumn{1}{|c|}{ ITEM } & Acceptable & $\begin{array}{c}\text { Needs } \\
\text { work }\end{array}$ & Comment \\
\hline Interface & & & \\
\hline Displays & & & \\
\hline Modes of presentation & & & \\
\hline Text layout & & & \\
\hline Text consistency & & & \\
\hline Graphics & & & \\
\hline Sound & & & \\
\hline $\begin{array}{l}\text { Access to } \\
\text { Hyperlinks }\end{array}$ & & & \\
\hline Look and feel & & \\
\hline $\begin{array}{l}\text { Use and placement of } \\
\text { the logo }\end{array}$ & & & \\
\hline Font style/color/size & & & \\
\hline Use of colors & & & \\
\hline Overall screen layout & & & \\
\hline $\begin{array}{l}\text { Look and placement of } \\
\text { Buttons }\end{array}$ & & & \\
\hline
\end{tabular}

\begin{tabular}{|l|l|l|l|}
\hline \multicolumn{1}{|c|}{ ITEM } & Acceptable & Needs work & Comment \\
\hline Navigation & & & \\
\hline Navigation aids & & & \\
\hline Consistency & & & \\
\hline Passive bookmarking & & & \\
\hline
\end{tabular}

\begin{tabular}{|c|l|l|l|}
\hline \multicolumn{1}{|c|}{ ITEM } & Acceptable & Needs work & Comment \\
\hline Pedagogy & & & \\
\hline $\begin{array}{l}\text { Methodologies } \\
\text { Opportunities for: } \\
\text { Listening practice }\end{array}$ & & & \\
\hline Reading practice & & & \\
\hline Writing practice & & & \\
\hline Interactivity & & & \\
\hline
\end{tabular}


ALLS 7(6):36-45, 2016

\begin{tabular}{|l|l|l|l|}
\hline Production/comprehension & & & \\
\hline Attention and perception & & & \\
\hline Scaffolding & & & \\
\hline Learning strategies & & & \\
\hline Planning tasks & & & \\
\hline $\begin{array}{l}\text { Evaluating } \\
\text { performance }\end{array}$ & & & \\
\hline User control & & & \\
\hline $\begin{array}{l}\text { Degree of control } \\
\text { Method of control }\end{array}$ & & & \\
\hline Responses and feedback & & & \\
\hline $\begin{array}{l}\text { Placement of questions } \\
\text { Item types }\end{array}$ & & & \\
\hline $\begin{array}{l}\text { Availability of } \\
\text { answers }\end{array}$ & & & \\
\hline Nature of feedback & & & \\
\hline
\end{tabular}

\begin{tabular}{|c|c|c|c|}
\hline \multicolumn{1}{|c|}{ ITEM } & Acceptable & Needs work & Comment \\
\hline Invisible features & & & \\
\hline Data collection & & & \\
\hline
\end{tabular}

\begin{tabular}{|l|l|l|l|}
\hline \multicolumn{1}{|c|}{ ITEM } & Acceptable & Needs work & Comment \\
\hline \multicolumn{1}{|c|}{ Robustness } & & & \\
\hline $\begin{array}{l}\text { Flexibility of the program } \\
\text { with different computers } \\
\text { software. }\end{array}$ & & & \\
\hline $\begin{array}{l}\text { Compatibility with different } \\
\text { browsers and bandwidths }\end{array}$ & & & \\
\hline $\begin{array}{l}\text { Adaptability to future } \\
\text { changes }\end{array}$ & & & \\
\hline
\end{tabular}

\begin{tabular}{|l|l|l|l|}
\hline \multicolumn{1}{|c|}{ ITEM } & Acceptable & Needs work & Comment \\
\hline Supplementary materials & & & \\
\hline Printable materials & & & \\
\hline Program operation-manual & & & \\
\hline Instructor manuals & & & \\
\hline $\begin{array}{l}\text { Other sources (links to other } \\
\text { Websites) }\end{array}$ & & & \\
\hline
\end{tabular}

Additional comments: 


\section{MASSKA SUTMTHER CADEMIC PROGRAM}

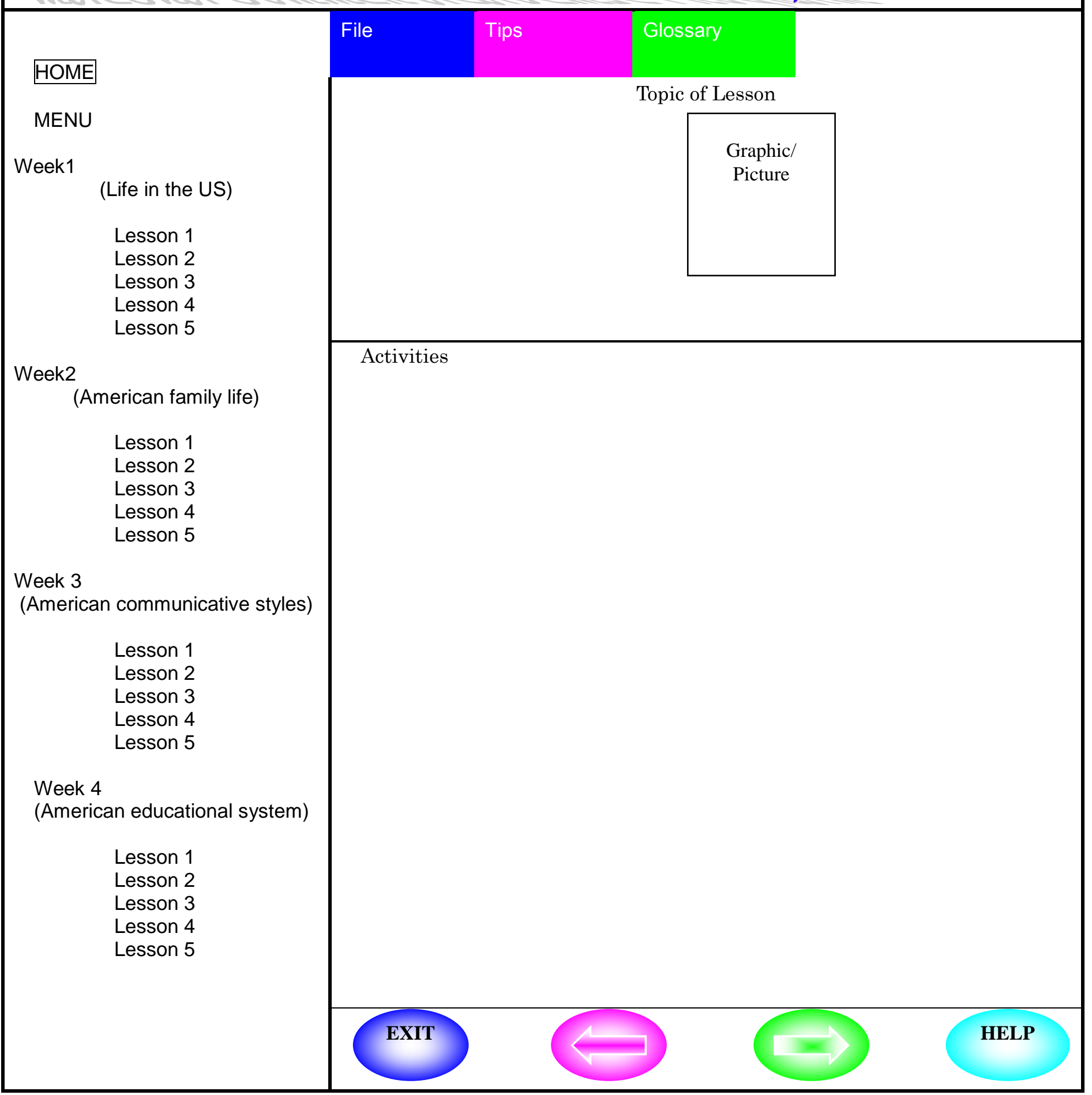




\section{SUMMER ACADEMIIC PROGRAM}

MENU

$\underline{\text { Lesson }}$

$\underline{\text { Home Stay }}$

Activity

Campus Life

BEAUTIFUL Experience!

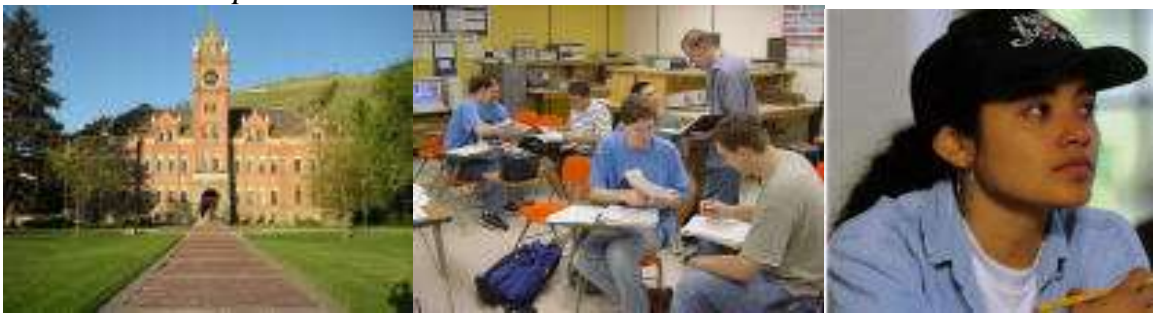

EXCELLENT Program! FOUR FEATURES
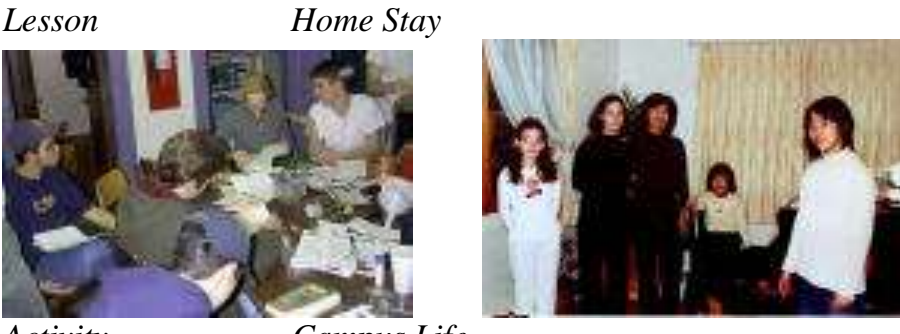

Activity Campus Life
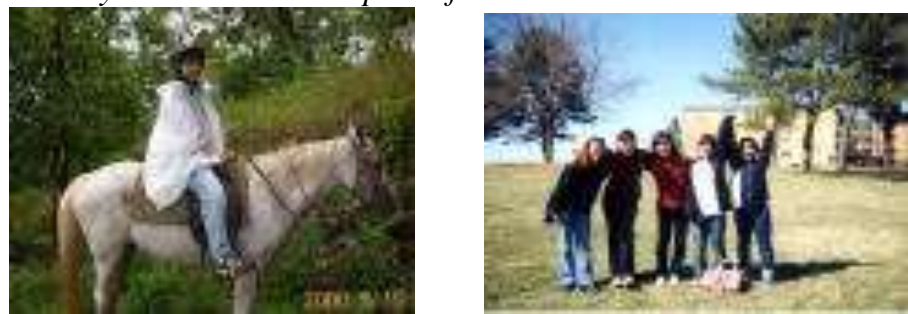

Lesson

Students can study in local university!

Home stay

Students live with their host family!

Activity

Students can experience variety of activities!

Campus Life

Students can experience school life in university!
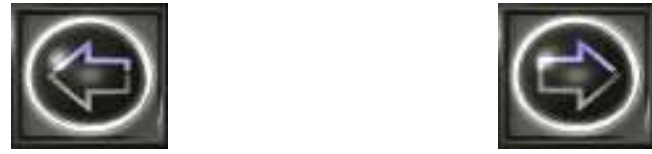


\section{Appendix D \\ Primary/secondary texts}

Week (3): What is the Communicative Style of Americans?

\section{Introduction:}

Another way of describing differences between people from diverse cultural backgrounds, besides comparing their values, is comparing their communicative styles. When people with differing communicative styles interact, they frequently feel ill-at-ease, and they often misjudge or misunderstand each other. To help understand why that happens, and to try to reduce the communications problems that arise when it does happen, it is helpful if foreigners (anywhere, not just in the U.S.) know something about the communicative style of the local people, and the way it compares with their own communicative style. With that knowledge, the foreigners will be better able to understand what is happening when they are dealing with the local people, and will know some of the ways in which the local people are likely to misunderstand or misjudge them.

Learning objectives: Students will be asked to read excerpts that pertain to the communicative style of Americans. The emphasis will for this week will be to build and reinforce vocabulary skills, and reading comprehension. Writing practice will be highlighted and discussions of writing assignments will be completed in class.

\section{Lesson (1)}

Directions: Warm up Writing Practice: In an email to your teacher, please write a short response to the following question. Be sure to print out and bring your response to class tomorrow for the class discussion.

Prompt: Imagine it is your first day of class. The class is made up of students from all over the world and

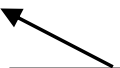

Secondary there are people from the U.S., France, Great Britain, Japan, and Latin American. Brainstorm as many stereotypes that you can that describe the communication styles of each of these students. 